\title{
Penerapan Haversine Formula Pada Penerimaan Peserta Didik Baru Jalur Zonasi
}

\author{
Sakti Winoto ${ }^{1}$, Abdul Fadlil ${ }^{2}$, Rusydi Umar ${ }^{3, *}$ \\ ${ }^{1}$ Program Studi Magister Teknik Informatika, Universitas Ahmad Dahlan, Yogyakarta, Indonesia \\ ${ }^{2}$ Program Studi Teknik Elektro, Universitas Ahmad Dahlan, Yogyakarta, Indonesia \\ ${ }^{3}$ Program Studi Teknik Informatika, Universitas Ahmad Dahlan, Yogyakarta, Indonesia \\ Email: ${ }^{1}$ saktiwinoto@yahoo.com , ${ }^{2}$ fadlil@mti.uad.ac.id, ${ }^{3,}{ }^{*}$ rusydiumar@ rocketmail.com \\ *) Email Penulis Korespondensi: rusydiumar@ rocketmail.com
}

\begin{abstract}
Abstrak-Pemerintah melalui kementrian Pendidikan dan kebudayaan mengeluarkan regulasi tentang penerimaan peserta didik baru yang diatur dalam Permendikbud Nomer 51 tahun 2018 menerapkan sistem zonasi. Peraturan tersebut menegaskan bahwa sekolah wajib memberikan prioritas kepada calon peserta didik yang berada dalam domisili radius terdekat dengan letak sekolah. Untuk memudahkan instansi terkait dan masyarakat dalam mendapatkan inforasi sekolah yang terdekat dalam suatu zona, maka perlu dibuat suatu sistem informasi yang dapat menyajikan informasi terkait keberadaan atau lokasi sekolah tersebut. Salah satu sistem yang dirancang untuk menyelesaikan dan bekerja dengan data yang direferensikan secara spasial atau koordinat geografis adalah Sistem Informasi Geografis (SIG). Sistem Informasi Geografis memiliki kemampuan untuk melakukan pengolahan data dan melakukan operasi-operasi tertentu dengan menampilkan peta dan mampu menganalisis data dengan baik. Penelitian yang dilakukan menerapkan formula haversine dalam pencarian lokasi sekolah terdekat. Untuk membangun peta digital menggunakan Google Maps, dan dikembangkan dengan layanan mobile.Google Maps API menyajikan fungsi-fungsi pemrograman yang disediakan oleh Google Maps untuk diintegrasikan dalam web atau aplikasi yang sedang dibuat. Sedangkan informasi tentang data sekolah disajikan dan diitegrasikan dalam aplikasi goegrafis.
\end{abstract}

Kata Kunci: Zonasi, SIG, Google Maps API, GPS, Haversine

Abstract-The government through the Ministry of Education and Culture issued a regulation on the admission of new students as stipulated in the Minister of Education Regulation Number 51 of 2018 to apply the zoning system. The regulation emphasizes that schools are required to give priority to prospective students who are in the domicile of the closest radius to the location of the school. To facilitate relevant agencies and the public in getting the closest school information in a zone, it is necessary to create an information system that can present information related to the existence or location of the school. One of the systems designed to solve and work with spatially referenced data or geographic coordinates is the Geographic Information System (GIS). Geographical Information Systems have the ability to perform data processing and freeze certain operations by displaying maps and able to analyze data properly. Research carried out applies the haversine formula in the search for the location of the closest school. To build digital maps using Google Maps, and developed with mobile services. The Google Maps API presents the programming functions provided by Google Maps for integration in the web or the application that is being created. While information about school data is presented and integrated in the goegraphic application.

Keywords: Zonasi, SIG, Google Maps API, GPS, Haversine

\section{PENDAHULUAN}

Perkembangan teknologi yang sangat pesat di berbagai bidang menuntut pula perkembangan teknologi informasi baik perangkat keras maupun perangkat lunaknya[1]. Hampir disemua sisi kehidupan manusia tidak terlepas dari teknologi berbasis komputer. Berbagai disiplin ilmu telah memanfaatkan teknologi untuk mengembangkan teoriteori dan aplikasi melalui berbagai macam cara[2]. Keadaan ini menempatkan internet yang merupakan salah satu dari bagian teknologi informasi dan komunikasi menjadi sarana yang penting dalam penerapan perkembangan ternologi disemua bidang. Seiring perkembangan teknologi tersebut, banyak sekali riset dan penelitian yang telah dilakukan untuk mendorong timbulnya penemuan baru dalam bidang teknologi informasi. Salah satu penemuan yang dalam bidang pemetaan dan geografi adalah Goegraphic Information System (GIS) [2].

Berdasarkan Permendikbud Nomer 51 tahn 2018 tentang penerapan jalur zonasi, maka sekolah yang diselenggarakan oleh pemerintah daerah diwajibkan untuk menerima calon peserta didik yang berdomisili pada radius zona terdekat dari sekolah paling sedikit sebesar 90 persen dari total jumlah peserta didik yang diterima. Selebihnya sebesar 10 persen dari total peserta didik yang diterima dibagi menjadi dua kriteria, yaitu 5 persen untuk jalur prestasi dan 5 persen untuk calon peserta didik yang mengalami perpindahan domisili.

Cara yang digunakan untuk mengukur jarak dari tempat tinggal dengan sekolah ditentukan oleh sekolah masing-masing yang dikuatkan dengan Surat Keputusan Bupati yang mengatur tentang zonasi dan jarak dalam wilayah tertentu. Dengan menggukana sistem yang digunakan saat ini ada kemungkinan masih terdapat wilayah yang seharusnya masuk dalam wilayah zona namun tidak tertulis dalam surat keputusan yang sudah ditetapkan oleh pemerintah tingkat kabupaten. Hal ini masih dirasa merugikan masyarakat yang berada pada wilayah yang lebih dekat dengan zona yang sudah ditentukan tetapi tidak masuk dalam keputusan bupati.

Berdasarkan uraian yang disampai diatas, maka permasalahan dalam penelitian ini dapat dirumuskan sebagai berikut: 1) Bagaimana merancang dan membuat Sistem Informasi Geografis (SIG) dalam penerimaan 
peserta didik baru berbasis mobile dengan menggunakan Google Maps API? 2) Bagaimana sistem informasi geografis (SIG)dapat membantu dalam penerimaan peserta didik baru melalui jalus zonasi?

Penelitian yang dilakukan ini bertujuan untuk membuat suatu rancangan Sistem Informasi Geografis (SIG) yang dapat digunakan untuk membantu pemetaan dalam penerimaan peserta didik baru jalur zonasi. Aplikasi dengan menerapkan Sistem Informasi Geografis (SIG) berbasis mobile merupakan salah satu cara untuk membantu para orang tua dan calon pendaftar dalam mengakses informasi sekolah terdekat yang masuk dalam zonasi. Sistem aplikasi ini dirancang untuk memberikan kemudahan para pengguna dapat mengakses dan mendapatkan informasi tentang zonasi sekolah dan informasi lain[3]. Diharapkan penelitian yang penulis lakukan bermanfaat untuk:

a. Bagi pemerintah

Sistem ini diharapkan memberikan kemudahan bagi Dinas Pendidikan dalam memberikan informasi kepada masyarakat tentang pemetaan lokasi sekolah yang berkaitan dengan posisi atau letak tempat tinggal calon peserta didik baru melalui sistem zonasi.

b. Bagi masyarakat

Dengan sistem yang dirancang berbasis mobile/smartphone ini akan memberikan kemudahan kepada masyarakat dalam mencari informasi tentang letak geografis pada tampilan peta dan navigasi sekolah yang masuk dalam zona terdekat memalui smartphone yang dimikinya.

c. Bagi peneliti

Penelitian yang dilakukan ini diharapkan akan dapat menambah wawasan peneliti tentang Sistem Informasi Geografis (SIG) dan peralatan teknologi informasi lainnya yang dapat digunakan untuk membantu menentukan pemetaan dalam penerimaan peserta didik baru melalui jalur zonasi.

\section{METODE PENELITIAN}

\subsection{Sistem Informasi Geografis (SIG)}

Sistem Informasi Geografis (SIG) merupakan perangkat teknologi infomasi yang digunakan untuk membuat, memanipulasi dan menganalisis terhadap data base yang bereferensi geografis untuk menghasilkan suatu peta baru dan data atribut. Dalam pemanfaatan Sistem Informasi Geogafis membutuhkan data spasial yaitu data yang berkaitan dengan ruang atau lokasi pada permukaan bumi[4]. Sistem Informasi Geografis dapat mengelola informasi geografis secara integrasi, dengan menampakkan pemodelan suatu permukaan bumi dalam suatu layer dan dapat dilakukan tumpang susun (overlay) dengan informasi-informasi yang lain[5]. Didalam Sistem Infomasi Geografis terdapat perpaduan antara komponen-komponen perangkat keras, perangkat lunak, data grafis, dan manusia sebagai pengguna yang secara efektif bekerjasama untuk memasukkan, menyimpan, memperbaiki, melakukan pembaruan, melakukan pengelolaan manipulasi, mengintegrasikan dan menyajikan informasi dalam suatu bentuk grafis[6].

\subsection{Model Data Dalam Sistem Inomasi Geografis}

Data spasial merupakan suatu kombinasi yang berupa tanda-tanda khusus berupa karakter yang dipakai untuk mengatur bentuk tanda tampilan. Data spasial dapat diperoleh dari beberapa sumber, antara lain: peta analog, data hasil pengukuran lapangan dan data yang diperoleh dari GPS. Format data spasial dalam Sistem Informasi Geografis dibedakan menjadi dua format, yaitu format data vektor dan format data raster. Simbol-simbol dalam Sistem Informasi Geografis yang mewakili model data vektor disebut feature. Simbol dari model data vektor berupa kumpulan garis(line), polygon, atau area (surface) yang merupakan wilayah yang dibatasi dengan garis pada awal dan akhir suatu titik yang sama. Selain itu simbol data vektor juga bisa berupa titik (node) yang merupakan titik perpotongan antara dua buah garis.

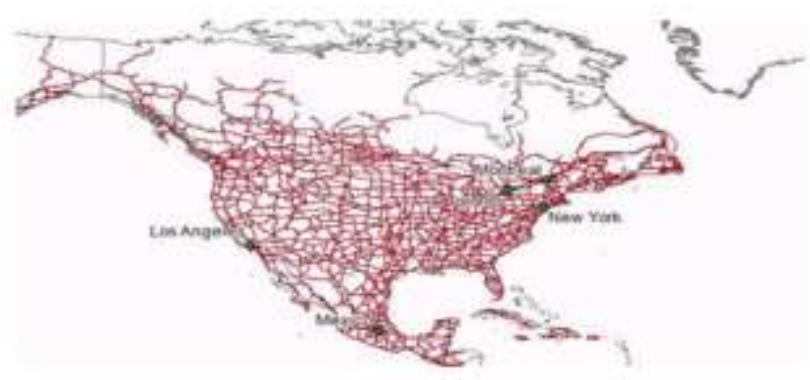

Gambar 1. Formad Data Vektor

Data raster merupakan data yang dihasilkan dari penginderaan jauh. Data raster juga biasa disebut dengan istilah sel grid karena obyek geografis ditampilkan dalam struktur sel grid yang disebut dengan pixel[7]. Berikut ini adalah gambar model data raster. 


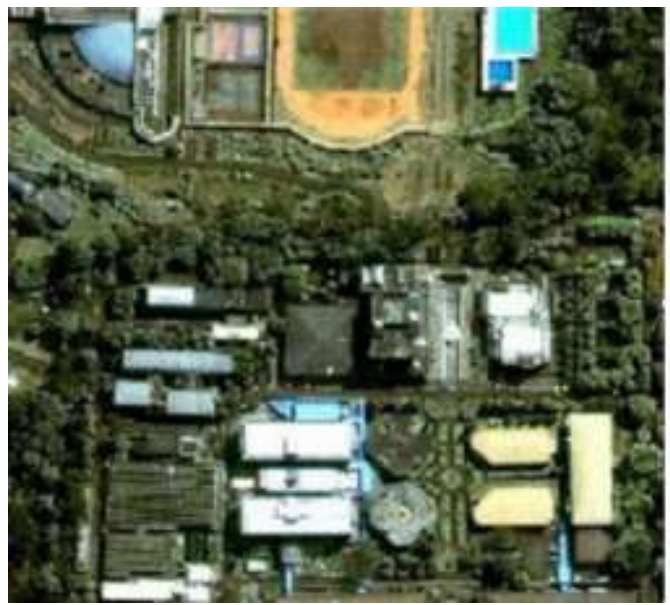

Gambar 2. Model Data Raster

\subsection{Unified Modelling Language (UML)}

Suatu perancangan dalam sistem berorientasi obyek dikenal UML atau Unified Modelling Language, yaitu suatu metode pemodelan visual atau gafis yang digunakan untuk mendesain dan memudahkan dalam mendeskripsikan sistem perangkat lunak. UML merupakan bahasa yang berupa aturan dan spesifikasi srandar dalam membuat dokumentasi, spesifikasi, kalkulasi, visualisasi, proses analisa, gambaran kerja proses serta perancangan sebuah sistem perangkat lunak. Mulai dari kebutuhan sistem sampai implementasi sistem, UML memenuhi persyaratan karena didalamnya tercakup diagram alernatif untuk menjelaskan statis properti, penggunaan sistem atau komponen dan sistem arsitektur.

\subsection{Google Maps API}

Google Maps API (Application Programming Interface) merupakan sekumpulan komponen yang melakukan bebagai fungsi yang berhubungan dengan pemetaan. Google Maps API memberikan dua versi yaitu standar dan bisnis. Versi lisensi yang dikeluarkan Google dibatasi paling banyak 25.000 akses. Platform dalam Google Maps $A P I$ ada 4 bagian, yaitu Android, iOS, Web dan Web service. Untuk Web service merupakan layanan yang bersifat platform netral, artinya bisa bisa digunakan untuk membangun aplikasi mobile, web, desktop, dan embeded system seperti GPS tracker pada mobil. Layanan-layanan yang diberikan oleh Google Maps API dapat dimanfaatkan oleh pengguna dengan melakukan registrasi dan mendapatkan Google Maps API Key untuk membuat petanya sendiri[8].

\subsection{Global Positioning System (GPS)}

Glogal Positioning System (GPS) mulai diperkenalkan pertama kali oleh Departemen Pertahanan Amerika Serikat pada tahun 1978. GPS digunakan untuk menentukan posisi yang berbasis satelit berdasarkan titik koordinat lintang dan bujur dipermukaan bumi. Dari segi kualitas dan operasionalitasnya GPS dapat dihandalkan dan mempunyai banyak kelebihan dibandingkan dengan metode penentuan posisi yang lain, sehingga GPS banyak diaplikasikan dan dimanfaatkan untuk membuat sistem informasi yang berkaitan dengan posisi dan penghitungan jarak.

Dengan menggunakan GPS, keberadaan lokasi pengguna akan dapat diketahui secara akurat karena GPS memanfaatkan receiver yang mampu berkomukasi dengan satelit. Satelit akan mengirimkan data berupa sinyal radio dan data digital sehingga GPS mampu memberikan informasi tentang petunjuk arah dimanapun berada. Pengguna dapat memanfaatkan layanan ini secara gratis.

\subsection{Geolocation}

Geolocatin merupakan salah satu metode yang digunakan untuk mengetahui dan menemukan letak suatu lokasi. Melalui komputer atau telepon seluler seseorang dapat diketahui keberadaan lokasinya dengan memanfaatkan IP Address, sambungan wireless BTS, dedicated GPS atau embeded GPS pada seluler.

\subsection{Pengumpulan Data}

a. Observasi

Dalam pengumpulan data metode ini, dilakukan pengamatan langsung di lokasi tempat penelitian yaitu Dinas Pendidikan Kabupaten Klaten dan SMP Negeri 2 Manisrenggo. Kegiatan yang dilakukan bertujuan untuk mendapatkan data dengan cara mencatat, mengamati, dan menggali informasi yang berkaitan dengan obyek penelitian yang meliputi nama sekolah negeri yang terdapat di kabupaten Klaten, alamat sekolah, daya tampung tiap-tiap sekolah, dan informasi lain yang dibutuhkan.

b. Studi Literatur 
Metode pengumpulan data dengan studi literatur ini dilakukan dengan membaca buku atau referensi dokumentasi yang terkait dengan penelitian tentang penentuan lokasi dan penghitungan jarak. Selain itu melakukan juga pencarian informasi di internet untuk mendapatkan data atau sumber-sumber yang berhubungan dengan obyek penelitian. Setelah sumber data dan informasi dapat dikumpulkan, selanjutnya mempelajari dan menelaah untuk mendapatkan landasan dalam melaksanakan penelitian. Sumber data dan informasi yang dijadikan acuan tersebut bersumber dan merujuk pada buku bacaan, jurnal, tesis kan karya tulis ilmiah lainnya.

c. Metode Wawancara

Merupakan metode yang dilakukan dengan cara tanya jawab atau wawancara kepada pihak yang mempunyai kewenangan dan mempunyai kapasitas dan informasi yang dibutuhkan dalam pelaksanaan penelitian ini khususnya Dinas Pendidikan kabupaten Klaten.

\section{HASIL DAN PEMBAHASAN}

\subsection{Alat dan Bahan}

Peralatan pendukung yang digunakan dalam penelitian ini diperlukan sebagai penunjang dalam pelaksanaan dan pembuatan aplikasi. Alat pendukung ini berupa perangkat keras dan perangkat lunak. Berikut ini peralatan yang digunakan :

1. Hardware (Perangkat Keras)

Perangkat keras yang digunakan untuk membangun aplikasi ini adalah laptop dengan spesifukasi sebagai berikut:

Processor Intel(R) Pentium (R) CPU B950 @ 2.10 GHz (2 CPUs)

RAM 2 MB

Hard Disk $500 \mathrm{MB}$

2. Software (Perangkat Lunak)

Pembuatan aplikasi dalam sistem ini menggunakan perangkat lunak sebagai berikut:

Paket DataBase Managemen System (DBMS) yang digunakan adalah MySQL

Bahasa Pemrograman PHP dengan javascript untuk penlisan kode program

Menggunakan Google API untuk menampilkan peta

3. Sumber Data

Sumber dan jenis data yang digunakan adalah:

a. Primer

Data primer yang digunakan dalam aplikasi ini didapatkan dari koordinat lokasi sekolah yang diperoleh dari Google Maps API dan GPS

b. Sekunder

Jenis data sekunder merupakan hasi dari capture aplikasi tpacket capture pro dengan menggunakan cloudshark org.

\subsection{Diagram Konteks}

Pemodelan proses perancangan sistem disajikan dalam bentuk Data Flow Diagram (DFD). DataFlow Diagram (DFD) ini menggambarkan perancangan sistem yang akan dibangun dalam bentuk diagram konteks (context diagram), yang menjelaskan alur kerja sistem. Berikut ini adalah gambar diagram konteks:

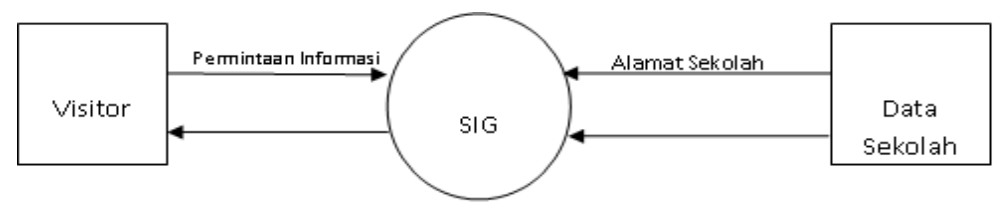

Gambar 3. Diagram Konteks

1. Perancangan Proses

Perancangan proses dalam pembuatan sistem ini akan mengintegrasikan keseluruhan informasi yang didapat dari data yang telah diperoleh serta aplikasi Googke Map API kedalam desain untuk mendapat keluaran informasi yang diharapkan, setelah proses dan interface selesai didesain, maka akan dibuat fungsi-fungsi yang diinginkan Berikut ini gambar diagram perancangan sistem yang akan dibuat:

2. Use case diagram

Perancangan proses ini digunakan untuk menggambarkan tahapan dan langkah yang dilakukan oleh visitor sebagai pengguna dan petugas atau admin yang mengelola sistem. Proses ini merupakan tahapan yang menjelaskan dan mendefinisikan fungsi dan fitur yang disajikan oleh sistem. Diagram use case sistem untuk 
Volume 4, Nomor 1, Januari 2020, Page 103-109

ISSN 2614-5278 (media cetak), ISSN 2548-8368 (media online)

Available Online at https://ejurnal.stmik-budidarma.ac.id/index.php/mib DOI 10.30865/mib.v4i1.1573

pengguna akan menampilkan peta lokasi yang dapat dilihat dan menampilkan informasi hasil pencarian letak sekolah terdekat dengan alamat pengguna.

a. Perancangan Proses

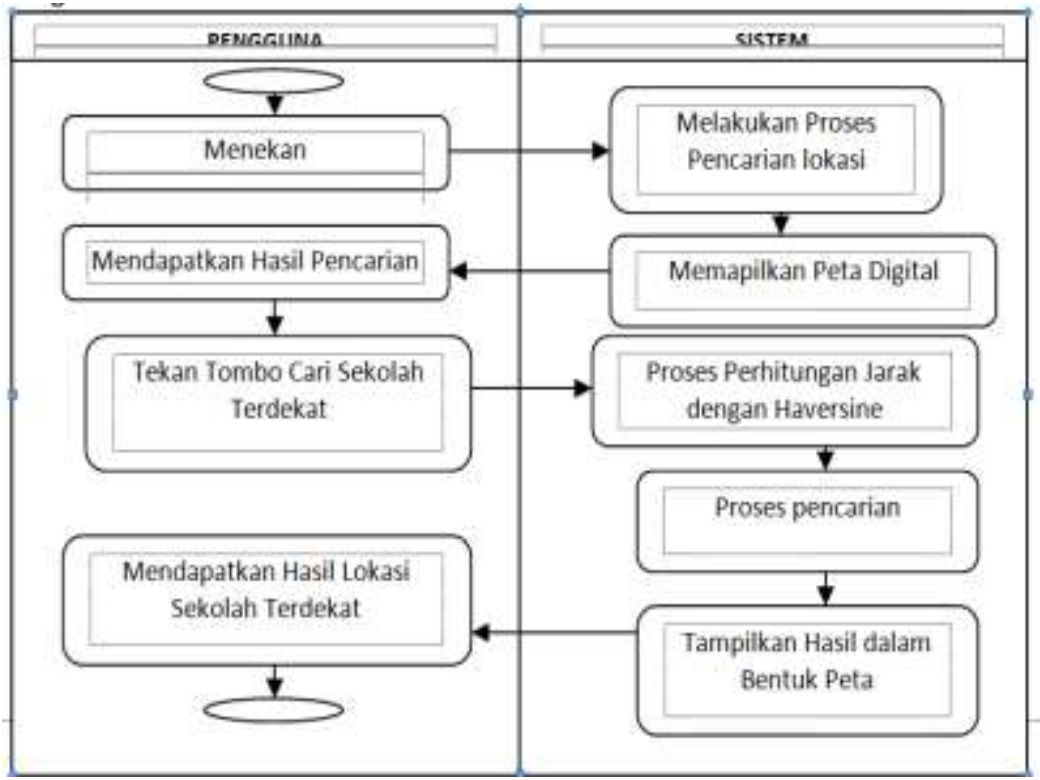

Gambar 4. Perancangan Proses

b. Use Case Pengguna

Berikut gambar diagram use case untuk pengguna.

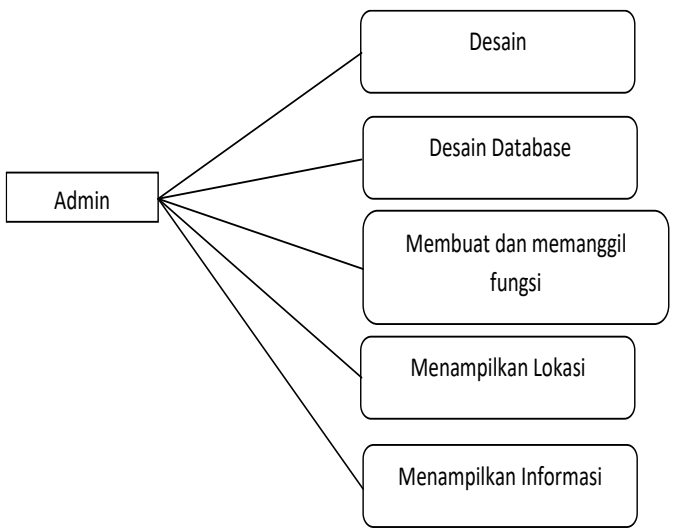

Gambar 5. Use case Di agram Pengguna

c. Use Case Admin

Use case admin atau petugas berperan melakukan pengelolaan terhadap informasi yang akan ditampilkan terkait dengan sekolah yang ada pada lokasi dalam suatu zonasi. Berikut ini gambar use case untuk admin.

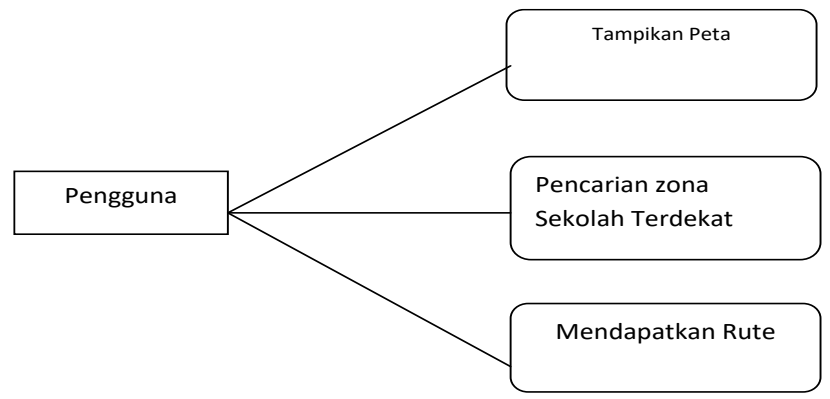

Gambar 6.Use case Diagram Admin

\subsection{Perancangan Sistem}

Langkah-langkah dalam pencarian jarak sekolah terdekat sebagai berikut: 
1. Pengguna memasukkan alamat tempat tinggal, kemudian sistem akan mendeteksi titik koordinat lintang dan bujur.

2. Secara otomatis sistem akan melakukan penghitungan antara jarak awal dengan posisi sekolah terdekat (sekolah ke-n) dengan menggunakan haversine formula yaitu:

$\mathrm{a}=\sin ^{2}(\Delta$ latDifference $/ 2)+\cos ($ lat 1$) * \cos ($ lat2 $\left.) \cdot \sin ^{2}\right) \Delta$ difference $\left./ 2\right)$

$\mathrm{c}=2 \cdot \operatorname{atan} 2(\sqrt{ } \mathrm{a}, \sqrt{ }(1-\mathrm{a})$

$\mathrm{d}=\mathrm{r}^{*} \mathrm{c}$

dimana,

$\Delta$ latDifference $=$ lat $1-$ lat 2 (perbedaan garis lintang)

$\Delta$ lonDifference $=$ lon 1 - lon2 (perbedaan garis bujur)

$\mathrm{R}$ adalah jari-jari bumi yaitu $6371 \mathrm{Km}$ atau 3961 mil, dengan 1 derajat= 0.0174532925 radian

$\mathrm{d}$ adalah jarak yang dihitung antara dua titik.

3. Jarak antara posisi awal dan posisi sekolah ke-n jika sudah diketahui, maka sistem melakukan pembandingan, jarak antara posisi awal sampai sekolah pertama dengan jarak dari posisi awal sampai sekolah ke-n.

4. Apabila dalam pembandingan ditemukan jarak yang lebih kecil, maka sistem akan mengambil jarak yang lebih kecil tersebut.

5. Proses pembandingan akan terus belanjut sampai keseluruhan jarak sekolah selesai dibandingkan.

6. Jarak yang mempunyai nilai paling kecil dijadikan sebagai solusi untuk menentukan jarak terpendek.

\subsection{Pengujian Sistem}

Penerapan penghitungan yang dilakukan dalam menentukan jarak antara dua titik kordinat yaitu kantor kepala desa tanjungsari dan SMP Negeri 2 Manisrenggo menggunakan haversine formula dalam penerapan hukum kosinus sebagai berikut:

1. Langkah pertama,

Pengguna menentukan titik awal Kantor Kepala Desa Tanjungsari Kecamatan Manisrenggo sebagai koordinat, yaitu -7.6986579, 110.4971946

2. Langkah kedua,

Menentukan titik koordinat SMP Negeri 2 Manisrenggo, yaitu -7.6966385, 110.5041736

3. Langkah ketiga,

Melakukan konversi antara titik pertama dan titik kedua dalam radiandengan menggunakan rumus sebagai berikut:

Kantor kepala desa Tanjungsari.

$$
\begin{aligned}
& \text { Radlat }_{1}=\frac{-7.6986579}{180} \times 3,14=-0,134298810033333 \text { radian } \\
& \text { Radlong }_{1}=\frac{110.4971946}{180} \times 3,14=1,92756217246667 \text { radian }
\end{aligned}
$$

SMP Negeri 2 Manisrenggo.

$$
\begin{aligned}
& \text { Radlat }_{1}=\frac{-7.6966385}{180} \times 3,14=-0,13426358272 \text { radian } \\
& \text { Radlong }_{1}=\frac{110.5041736}{180} \times 3,14=1,92768391724 \text { radian }
\end{aligned}
$$

4. Langkah keempat,

Memasukkan koordinat titik awal dan koordinat titik akhir dengan rumus haversine,

$\mathrm{c}=\mathrm{a} \cos (\sin ($ Radlat 1$) \times \sin ($ RadLat 2$)+\cos ($ Radlat 1$) x \cos ($ Ratlat 2$) \times \cos ($ Radlong 2$)$

5. Langkah kelima:

Hasil perhitungan c dikonversikan menjadi kilometer dengan mengalikan jari-jari bumi (R) yaitu sebesar 6371 dengan rumus : $d=R \times c$

Untuk mendapatkan jarak dipermukaan bumi antara dua koordinat lintang dan bujur sebagai variabel pada algoritma dari formula haversine diatasn dapat diselesaikan dengan persamaan :

$$
\operatorname{Jarak}(d)=2 \mathrm{r} * \arcsin \left(\sqrt{\sin ^{2}\left(\frac{\emptyset_{1}-\emptyset_{2}}{2}\right)+\cos \left(\emptyset_{1}\right) \cos \left(\emptyset_{2}\right) \sin ^{2}\left(\frac{\lambda_{1}-\lambda_{2}}{2}\right)}\right)
$$

Keterangan :

$\varnothing=$ latitude

$\eta=$ longitude

Berdasarkan rumus persamaan diatas, maka dapat diketahui jarak antara kantor kepala desa Tanjungsari sampai SMP Negeri 2 Manisrenggo adalah 0,801148108110353

Perancangan sistem dalam aplikasi penerimaan peserta didik baru denan sisten zonasi akan memampilkan fitur atau fungsi-fungsi sebagai berikut:

1. Peta virtual akan memampilkan lokasi user dan sekolah

2. Menampilkan informasi jarak terdekat dari posisi user ke sekolah 
Volume 4, Nomor 1, Januari 2020, Page 103-109

ISSN 2614-5278 (media cetak), ISSN 2548-8368 (media online)

Available Online at https://ejurnal.stmik-budidarma.ac.id/index.php/mib

DOI 10.30865/mib.v4i1.1573

3. Menampilkan informasi dan keterangan yang dibutuhkan tiap-tiap sekolah

4. Menampilkan rute, jarak dan jalan yang bisa ditempuh menuju sekolah terdekat.

Tahap pengujian aplikasi ini dilakukan sebagai berikut:

1. Tahap pertama yang harus dilakukan adalah mendownload file project setelah selesai membuat App Inventor Project dalam bentuk format file apk.

2. Tahap kedua menginstal aplikasi yang telah selesai didownload ke handphone yang didapat dari halaman design App Inventor.

3. Tahap yang ketiga adalah melakukan pengujian yang biasa disebut dengan istilah testing blackbox. Tahap ini merupakan implementasi sekaligus mengetahui apakah sistem yang dibuat dapar berjalan dengan baik sesuai rancangann actifity yang telah dibuat.

Dengan memanfaatkan Geolocation dari Google Maps API user akan mendapatkan hasil pencarian lokasi sekolah terderkat. Selanjutnya formula haversine akan mencari jarak terpendek dengan membandingkan seluruh data sekolah yang telah diimputkan antara titik koordinat pengguna dengan titik koordinat sekolah. Jarak terkecil yang didapat dari penghitungan dengan menggunakan formula haversine itulah yang dinyatakan sebagai jarak terpendek. Selanjutnya hasil perhitungan dan informasi tersebut akan ditampilkan secara visual melalui peta yang sudah dibuat dalam sistem. Koordinat defauld yang digunakan adalah dalam penghitungan jarak yaitu titik kooordinat sekolah dan ririk koordinat pengguna yang dimanfaatkan untuk menampilkan peta digital beserta rute dan arah melalui Google Maps API.

\section{KESIMPULAN}

Setelah dilakukan pengujian dan analisis, maka dapat disimpulkan bahwa dengan menggunakan sistem yang telah dibuat dapat dihasilkan dan ditampilkan lokasi jarak sekolah terdekat yang dilengkapi dengan tampilan visual peta digital dan informasi terkait sekolah. Dengan menggunakan formula havesine bisa digunakan untuk mencari dan menentukan jarak lokasi terdekat dengan cara menghitung dan mendapatkan hasil yang nilainya paling kecil sebagai lokasi jarak terpendek.

Informasi data sekolah yang disajikan didalam aplikasi geografis tentang lokasi sekolah dan menampilkan data-data informasi sekolah diantaranya nama sekolah, jenis sekolah, posisi lintang, posisi bujur, jumlah daya tampung murid berdasarkan rombel, dan alamat sekolah. Untuk memberikan manfaat yang lebih banyak, maka disarankan untuk menyempurnakan system dengan selalu mengupdate database untuk menampilkan informasi yang lebih banyak terkait dengan data sekolah.

\section{REFERENCES}

[1] M. . Setiawan, Rahman; Nama, G.F; Muhammad, "Rancang Bangun Sistem Informasi Geografis Layanan Pendidikan Kota Bandar Lampung," Electr. - J. Rekayasa dan Teknol. Elektro, vol. 3, no. 1, pp. 164-173, 2016.

[2] S. Winoto, A. Fadlil, and R. Umar, "Perancangan sistem Penerimaan Peserta Didik Baru Jalur Zonasi dengan sistem Informasi Geografis (GIS) Berbasis Mobile,” Pros. Semnastek 2019, vol. 1, no. 1, pp. 668-676, 2019.

[3] R. Nurtantyana, "Pengembangan Aplikasi Mobile Direktori Smk Sebagai Informasi Lokasi Sekolah Menengah Kejuruan (Smk) Di Kota Yogyakarta Pada Platfrom Android," J. Elektron. Pendidik. Tek. Inform., vol. 5, no. 2, pp. 110,2016

[4] K. M. R. Alditra, A. Yudhana, and R. Umar, "Membangun Rancangan Sistem Informasi Menggunakan Berbasis Web Mobile ( Studi Kasus : Toko Kgs Rizky Motor )," Semin. Nas. Inform., vol. 2018, no. semnasIF, pp. 92-95, 2018.

[5] D. Soyusiawaty, R. Umar, and R. Mantofani, "Sistem Informasi Geografis Objek Wisata Propinsi Kepulauan," Semin. Nas. Apl. Teknol. Inf. 2007, vol. 27, no. 13, pp. 22-42, 2007.

[6] R. Umar, M. Aziz, and W. D. Rahardiyan, "PERINGATAN DINI PENANGGULANGAN PENYEBARAN HAMA WERENG COKLAT DENGAN SISTEM INFORMASI GEOGRAFIS,” SNTT VI, pp. 100-107, 2018.

[7] M. P. DEWI, "APLIKASI PEMETAAN GPS SMP SMA SURAKARTA BERBASIS MOBILE ANDROID," UNIVERSITAS MUHAMMADIYAH SURAKARTA, 2015.

[8] E. Budiman, "Pemanfaatan Teknologi Location Based Service Dalam Pengembangan Aplikasi Profil Kampus Universitas Mulawarman Berbasis Mobile," Ilk. J. Ilm., vol. 8, no. 3, p. 137, 2016. 